\title{
Knowledge and awareness regarding Chikungunya: a cross-sectional study among healthcare students in a private university, Malaysia
}

\begin{abstract}
Basic information on knowledge towards mosquito borne diseases is crucial to establish a progressive track on its prevention to defeat the challenges faced by epidemic breakdowns.

Objective: To evaluate the knowledge of healthcare profession students regarding Chikungunya, the Aedes Aegypti borne disease.

Method: A cross sectional, observation study was conducted in a private university, Kedah state, Malaysia among medical, pharmacy and dentistry students through convenience sampling using pre-validated questionnaire. The data was collected after taking written informed consent forms.

Results: A total of 636 healthcare students participated in the study with a response rate of $68 \%$. Most of the respondents (93\%) were aged 21 to 23 years, more than half $(63 \%)$ were females, three-forth $(78 \%)$ were Chinese and nearly half $(44 \%)$ were from medical faculty and $38 \%$ from year three education. Overall, only 85 participants (13\%) scored good knowledge score, whereas 283 participants (45\%) scored moderate and $268(42 \%)$ participants scored poor knowledge score towards Chikungunya virus. There was a statistically significant association observed among the field of study $\left[\mathrm{X} 2(4, \mathrm{~N}=636)=12.235, \mathrm{p}=.016^{*}\right]$ and year of study $[\mathrm{X} 2(4, \mathrm{~N}=636)=42.013$, $\mathrm{p}<.001]$ category respectively towards knowledge score. Among the participants' the knowledge score of Chikungunya showed better scores in the age group of 18$20(20 \%)$ with females $(15 \%)$, Chinese $(15 \%)$, pharmacy students $(19 \%)$ and year 2 $(25 \%)$ students showing better knowledge scores.

Conclusion: Overall, the healthcare students in AIMST University showed moderate knowledge score towards chikungunya however, educational intervention programmes can further enrich their knowledge in the prevention and management of these deadly infections.
\end{abstract}

Keywords: knowledge, mosquito borne diseases, aedes aegypti, healthcare, chikungunya, patients, infection
Volume 5 Issue 6 - 2018

\author{
Abdul Nazer Ali,' Chew Jia Hui,' Sunil K \\ Prajapati,' Nazer Zulfikar Ahmed ${ }^{2}$ \\ 'Faculty of pharmacy,AIMST University, Malaysia \\ ${ }^{2}$ Cognizant Technology Solutions India Private Limited, India
}

Correspondence: Abdul Nazer Ali, Faculty of pharmacy, AIMST University, Semeling, 08100 Bedong,

Kedah Darul Aman, Malaysia, Email abdul.nazarali16@gmail.com

Received: October II, 2018 | Published: November 09, 2018

\section{Introduction}

Mosquitoes are small, midge-like flies from Culicidae family are blood-sucking insects, breeding on stagnant water to reproduce. The female mosquitoes feed on blood and sometimes transmit germs while feeding to the host. ${ }^{2}$ Mosquitoes spread deadly diseases without affecting themselves. Not only mosquitoes carry diseases that afflict humans and animals, they can also cause severe skin irritation through allergic reaction causing bumps and itching.

Mosquito-borne diseases are caused by bacteria, virus or parasites leading to annual death of over one million people, worldwide. Mosquito-borne diseases include malaria, filariasis and viral infections such as dengue, chikungunya and Zika. The most important viruses include flaviviruses such as Zika and Dengue virus (DENV). ${ }^{3}$ Around the world, this species can efficiently transmit viruses that cause human illnesses such as yellow fever, dengue, Chikungunya and Zika. ${ }^{4}$

Chikungunya was first identified in Tanzania in the early 1952 and has caused periodic outbreaks in Asia and Africa, since 1960s. Outbreaks are often separated by periods of more than 10 years. ${ }^{5}$ In late 2013, the first local transmission of chikungunya virus in the Americas was identified in Caribbean countries and territories.
Since then, local transmission has been identified in 45 countries or territories throughout the Americas with more than 1.7 million suspected cases reported to the Pan American Health Organization from affected areas. ${ }^{6}$

According to Ministry of Health, Malaysia, from 15 February, 2017 to 2 March, 2017 about 50 cases of Chikungunya infection has been identified with positive blood results. The symptoms that appeared on patients include fever, rashes, severe joint paint, headache and conjunctivitis. ${ }^{7}$ Mosquitoes borne diseases are one of the significant public health problems in Malaysia. The increasing incidence of mosquito borne disease should draw attention from all individuals. Mosquitoes borne disease in Malaysia in recent years warrants a proactive approach for their prevention. Knowledge and use of personal protective measures presents an effective and important strategy for prevention and control of mosquitoes borne diseases. The primary vector, Aedes aegypti mosquito also carried chikungunya to the Caribbean islands; the first cases of this debilitating disease seen in the region of the Americas. The chikungunya outbreak spread to several countries in the WHO South-East Asia Region, including India, where 1400,000 cases were reported during $2006 .{ }^{8}$ Chikungunya is a painful and debilitating disease which can prove fatal and have experienced epidemics in recent years. Among infected humans, 80 to $90 \%$ of 
those infected with chikungunya develop symptoms like fever, rash, or severe joint pain. The symptoms often continue long after the body has cleared itself of the virus.

The mosquito borne diseases are major healthcare issues that drew attention from each and every individual, and the knowledge level regarding chikungunya was poor, the need to assess and evaluate the knowledge of future healthcare professionals becomes significant. Therefore, a significant preventive and protective measure has to be implemented to improve the knowledge and awareness of this virus to help with the breakthrough of the mosquito borne diseases in Malaysia.

\section{Outcome measures}

The outcome measure of the study was to assess the knowledge and awareness regarding Chikungunya among undergraduate healthcare students in a private university in Malaysia.

\section{Methods and material}

\section{Study design, site, target study population and period of study}

A cross sectional, with knowledge as a single dependent variable carried out in a private university (AIMST University), involving students from healthcare professional courses (medicine, dentistry, pharmacy) in second, third and fourth year of study. The study was conducted between January, 2017 and April, 2017.

\section{Inclusion/exclusion criteria}

Students who have studied the courses microbiology and/or pathology during their course of study, studying in second, third and fourth year of study and those willing to participate and signed the informed consent form were included in the study. Those involved in the pilot study, other than medicine, dentistry pharmacy courses and incomplete survey forms were excluded.

\section{Development and validation of the questionnaire}

The questionnaire was adapted from previous literatures and modified according to the need of the present study and consisted of socio-demographic details such as age, gender, ethnicity, and a section on knowledge based items using close-ended questions (Yes, No) comprised of progression of the disease; signs and symptoms; diagnosis; risk factors; treatment options; vaccine etc. The questionnaire was prepared with reference to WHO fact sheet and CDC: Chikungunya virus. ${ }^{9-11}$ One point was given for correct answer and zero point for incorrect answer. A higher score indicates better knowledge. The questionnaire was developed in English as the questionnaire will be distributed among healthcare student at undergraduate level where medium of instruction is English.

\section{Validation of the questionnaire}

The validation of the questionnaire was aimed to assess the ease of comprehension, relevance and effectiveness in providing information and degree to which the questions are interpreted and understood correctly to address the study objectives. The final questionnaire was content validated by six academicians from clinical pharmacy and pharmacy practice unit belonging to the faculty of pharmacy, AIMST University.

After the content validity by the expert panel was satisfactory, the questionnaires were face validated among 36 students, 12 from each participating faculty followed by instructions regarding the filling of questionnaire. The participants were encouraged to inquire any doubt or confusing items. Such items were explained in a more understandable manner and noted for later adjustment. Once completed, the results were analysed to validate the degree of understanding within a group. All recommendations found appropriate were considered and modified wherever necessary to reflect the pre-testing results. Thus the final version of the knowledge-based questionnaire was arrived.

A pilot study $(\mathrm{N}=36)$ to determine the Cronbach's alpha coefficient value in order to test the validity and reliability of the study tool was carried out and the alpha value was found to be .857 and showed good internal consistency. ${ }^{12,13}$

\section{Modality of obtaining response}

The students were explained verbally, on the aim and objectives of the study and the questionnaires were distributed to the students who were willing to participate in the study after signing their informed consent. The average time of 15 minutes was taken to complete the questionnaire and the completed questionnaires were retrieved and compiled for data analysis.

\section{Sample Size calculation}

The total population of the three targeted faculties as per inclusion criteria were approximately 1000 students. The study conducted utilized this figure as prevalence of students' population from which the sample size was calculated using on-line Raosoft sample size calculator. ${ }^{14}$ The estimated sample size was calculated at 95\% CI, 5\% margin of error with $50 \%$ response distribution and the sample size required was 278 . A $10 \%$ margin for drop-outs (28) was added to the sample size derived in order to overcome any errors and increase the reliability of the results and conclusion, the sample size was rounded off to a final sample of 300 .

\section{Ethical considerations}

The study was approved by Institutional Review Board (IRB), AIMST University Human Ethical Committee. Further, written permission from the deans of each participating faculty were obtained before approaching the students for the survey. Written signed informed consent forms were obtained from the participants explaining the aims and objectives of the study before survey form distribution.

\section{Scoring grades and scoring pattern}

The scoring grades attributed to overall knowledge was adopted from the Original Bloom's cut-off grade, scores of $80-100 \%$ correct response $(\geq 12)$ as good, $60-79 \%(9$ to 11$)$ as satisfactory and score $<60 \%(\leq 8)$ as poor. ${ }^{15,16}$

\section{Statistical analyses of data}

The survey data was tabulated using Microsoft Excel workbook and analysed using Statistical Package for Social Sciences 'SPSS version-23' (IBM SPSS Statistical software) for windows. The categorical variables were illustrated using descriptive statistics for frequency, percentage, median and IQR. The Chi-square test for independence was used to discover the association between categorical variables. The significance level was set at .05 levels for all statistical tests. The $p$-values were computed using Pearson's Chi Square test and $\mathrm{p}<.05$ was considered significant. All percentage are displayed in the text or in parentheses are with no decimal places as per APA reporting guidelines. 


\section{Results}

Among the 930 questionnaires distributed among the three faculty students, an overall response rate was $636(68 \%)$, and the dropouts were mainly due to incomplete questionnaires or unwilling to participate. The highest response rate within each faculty was obtained from dentistry $(79 \%)$ followed by pharmacy $(70 \%)$ and medicine $(63 \%)$.

\section{Demographic characteristics of the study population}

Majority of the respondents (93\%) were aged 21 to 23 years, more than half $(63 \%)$ were females, three-forth $(78 \%)$ were Chinese and nearly half $(44 \%)$ were from medical faculty and $38 \%$ from year three education (Table 1)

Table I Socio-demographic data of respondents $(\mathrm{N}=636)$

\begin{tabular}{lll}
\hline Variables & $\mathbf{N}$ & Percentage \\
\hline Age & & \\
$18-20$ & 20 & 3 \\
$21-23$ & 593 & 93 \\
$24-26$ & 23 & 4 \\
Gender & & \\
Male & 234 & 37 \\
Female & 402 & 63
\end{tabular}

Table Continued..

$\begin{array}{lcc}\text { Race } & & \\ \text { Malay } & 10 & 2 \\ \text { Indian } & 142 & 22 \\ \text { Chinese } & 484 & 76 \\ \text { Field of study } & \text { (Discipline) } & \\ \text { Medicine } & 282 & 44 \\ \text { Dentistry } & 143 & 23 \\ \text { Pharmacy } & 211 & 33 \\ \text { Years of Study } & & \\ \text { Year 2 } & 208 & 33 \\ \text { Year 3 } & 244 & 38 \\ \text { Year 4 } & 184 & 29\end{array}$

\section{Responses towards knowledge bases items on chikungunya}

Table 2 summarizes the top five questions that gained the highest correct responses (Questions 1, 4, 5, 11 and 12) and the five questions that obtained the lowest correct responses (Questions 2, 3, 6, 7 and 9). Overall, 85 participants (13\%) scored good knowledge score, whereas 283 participants $(45 \%)$ scored moderate and $268(42 \%)$ participants scored poor knowledge score towards Chikungunya virus.

Table 2 Proportion of correct responses towards knowledge based items $(\mathrm{N}=869)$

\begin{tabular}{|c|c|c|c|c|c|c|c|}
\hline \multirow[t]{2}{*}{ Qn.No } & \multirow[t]{2}{*}{ Knowledge items } & \multirow[t]{2}{*}{ Answer** } & \multicolumn{2}{|c|}{ Incorrect } & \multicolumn{2}{|c|}{ Correct } & \multirow[t]{2}{*}{ p-value } \\
\hline & & & $\mathrm{N}$ & (\%) & $\mathrm{N}$ & $(\%)$ & \\
\hline 1 & Chikungunya virus is most often spread by Aedes aegypti mosquitoes. & Yes & 158 & 25 & 478 & 75 & $<.001 *$ \\
\hline 2 & Chikungunya virus infection does not occur in cold temperature. & Yes & 338 & 53 & 298 & 47 & 0.113 \\
\hline 3 & Chikungunya virus cannot be transmitted through mother to child. & No & 311 & 49 & 325 & 51 & 0.579 \\
\hline 4 & Chikungunya virus can be transmitted through blood transfusion. & Yes & 202 & 32 & 434 & 68 & 0.973 \\
\hline 5 & Most people infected with chikungunya virus will develop some symptoms after 3-7 days. & Yes & 97 & 15 & 539 & 85 & $<.001^{*}$ \\
\hline 6 & All symptoms of chikungunya infection are same as with dengue fever and Zika fever. & No & 371 & 58 & 265 & 42 & $<.001 *$ \\
\hline 7 & The symptoms of Chikungunya can be severe and disabling, that often result in death. & No & 362 & 57 & 274 & 43 & $<.00 I^{*}$ \\
\hline 8 & Once a person has been infected, he or she is likely to be protected from future infections. & Yes & 313 & 49 & 323 & 51 & 0.692 \\
\hline 9 & Person infected with chikungunya tends to recover from joint problem within a few days. & No & 350 & 55 & 286 & 45 & $.01 I^{\wedge}$ \\
\hline 10 & Chikungunya infection can be prevented by vaccination. & No & 280 & 44 & 356 & 56 & $.003^{\wedge}$ \\
\hline II & $\begin{array}{l}\text { Reducing the natural and artificial water-filled container habitats can prevent and control } \\
\text { the chikungunya virus. }\end{array}$ & Yes & 100 & 16 & 526 & 84 & $<.001^{*}$ \\
\hline 12 & There is specific antiviral treatment for chikungunya. & No & 286 & 45 & 350 & 55 & $.01 I^{\wedge}$ \\
\hline 13 & Treatment for chikungunya is primarily directed at relieving the symptoms. & Yes & 107 & 17 & 529 & 83 & $<.00 I^{*}$ \\
\hline 14 & $\begin{array}{l}\text { Use of turmeric and ginger in regular diet may be effective as herbal remedies for } \\
\text { chikungunya. }\end{array}$ & Yes & 256 & 40 & 380 & 60 & $<.00 I^{*}$ \\
\hline 15 & Chikungunya virus infection is considered to be contagious. & No & 291 & 46 & 345 & 54 & $.032^{\wedge}$ \\
\hline
\end{tabular}

${ }^{* *}$ Correct answer key, pearson chi square test, significant at ${ }^{*} \mathrm{p}<.0 \mathrm{l}$ level; ${ }^{\wedge} \mathrm{p}<.05$ level.

Table 3 Association of knowledge score towards socio-demographic factors $(n=636)$

\begin{tabular}{|c|c|c|c|c|c|c|}
\hline \multirow[t]{2}{*}{ Variables } & \multicolumn{2}{|c|}{ Response distribution } & \multicolumn{3}{|c|}{ Knowledge score } & \multirow[t]{2}{*}{$P$ value } \\
\hline & $N$ & Percentage & Good & Moderate & Poor & \\
\hline \multicolumn{7}{|l|}{ Age } \\
\hline $18-20$ & 20 & 3 & $4(20)$ & $8(40)$ & $8(40)$ & 0.166 \\
\hline $21-23$ & 593 & 93 & $8 I(14)$ & $260(44)$ & $252(42)$ & \\
\hline
\end{tabular}

Citation: Ali AN, Hui CJ, Prajapati SK, et al. Knowledge and awareness regarding Chikungunya: a cross-sectional study among healthcare students in a private university, Malaysia. MOJ Bioequiv Availab. 2018;5(6):293-298. DOI: 10.15406/mojbb.2018.05.00II7 
Table Continued...

\begin{tabular}{|c|c|c|c|c|c|c|}
\hline $24-26$ & 23 & 4 & 0 & $15(65)$ & $8(35)$ & \\
\hline Gender & & & & & & 0.072 \\
\hline Male & 234 & 37 & $23(10)$ & $102(44)$ & $109(46)$ & \\
\hline Female & 402 & 63 & $62(15)$ & $|8|(45)$ & 159(40) & \\
\hline \multicolumn{7}{|l|}{ Race } \\
\hline Malay & 10 & 2 & $\mathrm{I}(10)$ & $4(40)$ & $5(50)$ & 0.272 \\
\hline Indian & 142 & 22 & II (6) & $7 I(50)$ & $60(42)$ & \\
\hline Chinese & 484 & 76 & $73(15)$ & $208(43)$ & $203(42)$ & \\
\hline \multicolumn{7}{|c|}{ Field of study (discipline) } \\
\hline Medicine & 282 & 44 & $30(11)$ & $|4|(50)$ & III(39) & $.016^{\wedge}$ \\
\hline Dentistry & 143 & 23 & $16(11)$ & $56(39)$ & $71(50)$ & \\
\hline Pharmacy & 211 & 33 & $39(18)$ & $86(4 I)$ & $86(4 I)$ & \\
\hline \multicolumn{7}{|c|}{ Years of study } \\
\hline Year 2 & 208 & 33 & $5 I(24)$ & $95(46)$ & $62(30)$ & $<.001 *$ \\
\hline Year 3 & 244 & 38 & $21(9)$ & $100(4 I)$ & $123(50)$ & \\
\hline Year 4 & 184 & 29 & $13(7)$ & $88(48)$ & $83(45)$ & \\
\hline
\end{tabular}

Pearsons chi square test, significant at ${ }^{*} \mathrm{p}<.01$ level; ${ }^{\wedge} \mathrm{p}<.05$ level.

Table 3 depicts, among the 636 participants, 14\% $(\mathrm{N}=81)$ from the age 21 to 23 years showed good knowledge score whereas $44 \%$ $(\mathrm{N}=260)$ showed moderate knowledge score and the remaining $42 \%$ $(\mathrm{N}=252)$ showed poor knowledge score. There was no statistical significance $\left[X^{2}(4)=6.473, \mathrm{p}=.166\right]$ observed among the age category towards knowledge score. Among the gender category, $44 \%(\mathrm{~N}=102)$ males and $45 \%(\mathrm{~N}=181)$ females showed moderate knowledge score towards Chikungunya. There was no statistical significance $\left[X^{2}(2)=5.266, \mathrm{p}=.072\right]$ observed among the gender category. Among the race category, 49\% ( $\mathrm{N}=80)$ Indians showed good score and $43 \%(\mathrm{~N}=208)$ Chinese showed moderate knowledge score towards Chikungunya Virus. There was no statistical significance $\left[\mathrm{X}^{2}(6)=7.564\right.$, $\mathrm{p}=.272]$ observed among the race category towards knowledge score. Among the field of study, 50\% ( N=141) from medicine showed moderate score and $50 \%(\mathrm{~N}=71)$ from dentistry and $(\mathrm{N}=86)$ from pharmacy showed poor or moderate knowledge score. There was a statistically significant association $\left[\mathrm{X} 2(4, \mathrm{~N}=636)=12.235, \mathrm{p}=.016^{*}\right]$ observed among the field of study category towards knowledge score. Among the year of study, $46 \%(\mathrm{~N}=95)$ from year 2 showed moderate score, whereas $50 \%(\mathrm{~N}=123)$ showed poor knowledge score and $48 \%(\mathrm{~N}=88)$ from year 4 showed moderate knowledge score towards Chikungunya. We observed a statistically significant association $[\mathrm{X} 2(4, \mathrm{~N}=636)=42.013, \mathrm{p}<.001]$ in knowledge score and year of study among the participants towards Chikungunya.

\section{Discussion}

Today's healthcare students are the future professionals living with mosquitoes borne disease, one of the major public health problems in Malaysia. It is therefore essential that healthcare students possess the appropriate and adequate knowledge regarding mosquito borne diseases and in particular Chikungunya, which is the prime reason behind our motivation to conduct this study. The results are prepared in comparison to the socio-demographics and the knowledge score differences among the various healthcare students of a private (AIMST) University.

This study was conducted to obtain clear picture as well as to assess knowledge towards mosquito (Aedes aegypti) borne disease, Chikungunya among undergraduate healthcare students. A total of 636 students from faculty of dentistry, medicine and pharmacy participated with a response rate of $68 \%$ and the drop-outs percentage was $32 \%$ mainly due to incomplete or blank survey forms, or unwilling to participate. Similar response rate $(61 \%)$ was found in a study conducted in University of Calgary, Faculty of Medicine, Canada which aimed to assess the level of stress among medical students, residents and graduate sciences students $(\mathrm{MSc} / \mathrm{PhD})$ and determine the types of stressor that trainees were experiencing. ${ }^{17}$

In this study, the participants age distribution were arranged into three categories of which, 21 to 23 years old (93\%) had an overwhelming participation. Statistically, no significant association was seen between the age categories. The mean age of current study population was 22 years. This study was consistent with the age group surveyed in Pakistan to determine the prevalence, attitude and knowledge of self-medication amongst university students with a means age of $21 \pm 1.8$ years. ${ }^{18}$ Yet, another survey conducted in Ziauddin Medical University, Karachi among medical students also had a mean age of $21 \pm 1.5$ years from pre-clinical and clinical years, consistent with the current study. ${ }^{19}$

In this study, there were more females (63\%) than male students (37\%). The female students ratio enrolled to the university was more than males which is commonly seen in other university as well in Malaysia. ${ }^{20,21}$ The support article revealed female students have different characteristics and inspiration that influence their educational achievement. This study involved Malay, Chinese and Indian students with no statistical differences between race categories. Most participants in this study were Chinese 484(76\%) with contrasted ethnical distribution from a University of Malaya study among medical students were mostly (52\%) Malays. ${ }^{22}$ Another survey among Universiti Sains Malaysia medical students also show similar contrasting ethnic distribution..$^{23}$ The reason for the unequal race distribution maybe due to the domination of Chinese student population in this private university campus. In addition, the entry into private universities is pretty straightforward, subject to seat 
availability and meeting the admission requirements for their desired course selection such as Medicine, Pharmacy and Dentistry.

There was a significant association $(\mathrm{p}<.05)$ in the course of study among the participants. This shows the participants were mostly from medical course followed by pharmacy course and dentistry. This difference may be due to the students intake in medical course is more (double) than other courses and the intake requirement of CGPA for medical admission is comparatively low (CGPA 3.0) when compared to other courses. Thus, there existed a direct relation between the number of students in each course and number of participants in this survey. This student distribution response was consistent with a study in Kuwait involving students from medicine (70\%), compared to relatively fewer enrolled pharmacy and dentistry students. ${ }^{24}$

There was a significant differences $(\mathrm{p}<.001)$ between year of study, majority were from Year $3(38 \%)$, followed by Year 2 $(33 \%)$ and year 4 students (29\%). The year 4 students showed least participation as most of them were exposed to clinical attachments in hospitals marking their unavailability for the survey. In contrast to current study, a study at the University of Toronto showed a different distribution among year 4 study $(86 \%) .{ }^{25}$ The survey should have been conducted at training sites.

The knowledge score toward Chikungunya virus showed about $44 \%$ of the participants in the age of 21 to 23 years showed moderate knowledge. The female responders had comparatively better knowledge which was consistent with a study conducted in University Putra Malaysia and a study performed in Nigeria on Ebola Virus. ${ }^{26,27}$ The race of respondents participated in this survey is highly inconsistent and predominated by Chinese. Among the course of study, pharmacy students showed better knowledge regarding Chikungunya. A similar result was reported in a knowledge survey conducted in Higher Education Commission-recognised Pakistani University regarding adverse drugs reaction in which pharmacy students had a significantly better knowledge about ADRs than medical students $($ mean $\pm \mathrm{SD}, 5.61 \pm 1.78$ vs. $3.23 \pm 1.60 ; \mathrm{P}<0.001) .{ }^{28}$ Moreover, the knowledge study performed in Kerman University of Medical Sciences reported pharmacy students had more general knowledge in all materials compared to other students $(p<.05)$, however, there was no significant difference between medical and dentistry students. ${ }^{29}$ Among year of study, $25 \%$ of second year participants showed good knowledge on Chikungunya Virus. The reason could be due to the exposure to microbiology and pathology courses during this period.

Overall, only $13 \%$ of students possess good knowledge regarding Chikungunya Virus. This finding is inconsistent with other findings. The reasons of low percentage of knowledge may due to low prevalence of Chikungunya in Malaysia during the study period, and indifferent attitude of students towards issues and topics not included in their curriculum. ${ }^{30}$ The top five questions which engross the highest correct responses were concerned with transmission, incubation period, prevention measure and treatment of Chikungunya respectively. These questions are basic, superficial and do not require specialised knowledge. However, the question 'Most people infected with Chikungunya virus will develop symptoms after 3-7 days' is answered correctly by $85 \%$ of responders. ${ }^{31}$ The prevention for mosquito breeding site was answered correct in $84 \%$. As the vector of chikungunya is similar to dengue virus which has high prevalence in Malaysia, the students may have obtained information regarding prevention of breeding of mosquito through social media. About $83 \%$ of responders agreed that treatment of chikungunya is focussed on relieving symptoms. In accordance to $\mathrm{CDC}$ fact sheet, no specific antiviral treatment is available for chikungunya. ${ }^{32}$ Symptomatic treatment includes: rest, fluids, use of analgesics and antipyretics. About $75 \%$ agreed the vector of Chikungunya is Aedes aegypti, which is inconsistent with two other studies, one with $97 \%$ correct response conducted among healthcare worker and the other with $41 \%$ correct response among medical students. ${ }^{33,34} \mathrm{~A} 68 \%$ correct response was obtained for transmission of CHIKV through blood transfusion. The risk of a person transmitting the virus through mosquito bite or blood is highest when the patient is viremic, usually during the first 2-6 days of illness.

On the other hand, the questions which obtained the lowest correct response were pertaining to geographical factor, symptoms, immunity and prognosis of Chikungunya infection. The symptoms of chikungunya are similar to those of dengue and Zika as they are sharing the same vector. Chikungunya symptoms include high fever, severe joint pain, joint swellings, muscle pain, head-aches and rashes. It is mostly non-fatal. However, only $43 \%$ of responder percept that CHIKV is non-fatal. $45 \%$ of responders acknowledged that the joint problems caused by CHIKV infection will recover within days. The severe joint pain and swellings can be persisted for months, even years depending on the viral load and individual health status. ${ }^{35}$ The CHIKV infection may occur in cold temperature as well, this knowledge is only discovered by $47 \%$ of responders. A single mutation in CHIKV provides a plausible explanation of how this mutant virus caused an epidemic in a region lacking the typical vector. This achievement enabled the virus to spread to Europe. ${ }^{35}$ Lastly, the immunity developed after first time infection is not well understood by students, only $51 \%$ responded correctly.

\section{Conclusion}

The knowledge of undergraduate healthcare students only possess superficial knowledge and insufficient information regarding chikungunya mostly due to passive learning attitude. As future healthcare professionals responsible to serve the society, it is important to improve the knowledge of mosquito borne diseases among healthcare students which can prevent additional burdens on all level of healthcare system. Hence, emphasis should be made to enhance knowledge and understanding of the healthcare students regarding mosquito borne diseases through workshops, presentations, and problem based learning. Strategies regarding educational interventions need to be designed and implemented.

\section{Limitations}

The limitation which restricted this survey include: most of the responders were females, uneven distribution of ethnicity, absenteeism of students during survey time and honesty of genuine response is suspected.

\section{Acknowledgements}

We are grateful to the study participants for their time and cooperation for this study.

\section{Author contributions}

All authors contributed toward data collection, data entry, analysis, drafting and critically revising the paper and agree to be accountable for all aspects of the work.

\section{Supplementary publications}

The author disclosure that there are supplementary manuscripts 
submitted for publications elsewhere with the source data and overlapping methods. However, the objective and scope of the manuscript has no overlapping information.

\section{Conflict of interest}

Author declares that there is no conflict of interest.

\section{References}

1. Jaeger Edmund C. A Source-Book of Biological Names and Terms. Springfield, Ill: Thomas; 1959 .

2. Kanzaria HK, Hsia RY. Mosquitoes and mosquito-borne diseases Wilderness Medicine. 6th ed. Philadelphia: Mosby; 2012.

3. Muktar Y, Tamerat N, Shewafera A. Aedes aegypti as a Vector of Flavivirus. J Trop Dis. 2016;4(223):2.

4. Jeffrey Powell. Zika isn't the only mosquito-borne virus that should worry us. 2016.

5. Chikungunya: World Health Organization

6. Chikungunya Virus. Centers for Disease Control and Prevention. Centers for Disease Control and Prevention; 2016.

7. From the Desk of the Director-General of Health Malaysia. 2017 Kenyataan Akhbar KPK 5 Mac-Situasi Semasa Demam Denggi, Zika dan Chikungunya di Malaysia.

8. Yellow fever. Centers for Disease Control and Prevention. National Center for Emerging and Zoonotic Infectious Diseases (NCEZID).

9. Aedes Chikungunya. Neglected Tropical Disease. World Health Organization (WHO).

10. Aedes Zika. Neglected Tropical Disease. World Health Organization (WHO).

11. Aedes Chikungunya. Neglected Tropical Disease. World Health Organization (WHO)

12. Henson RK. Understanding internal consistency reliability estimates: A conceptual primer on coefficient alpha. Measurement and evaluation in counseling and development. 2001;34(3):177-189.

13. Kahn J. Reporting statistics in APA style. 2011.

14. Raosoft I. Sample size calculator. 2004.

15. Kaliyaperumal KI. Guideline for conducting a knowledge, attitude and practice (KAP) study. AECS illumination. 2004;4(1):7-9.

16. John J. The knowledge, attitude, practice and perceived barriers towards screening for premalignant cervical lesions among women aged 18years and above, in Songea urban, Ruvuma (Doctoral dissertation, Muhimbili University of Health and Allied Sciences).2011.

17. Toews JA, Lockyer JM, Dobson DJ, et al. Stress among residents, medical students, and graduate science $(\mathrm{MSc} / \mathrm{PhD})$ students. Acad Med. 1993;68(10 Suppl):S46-S48.

18. Zafar SN, Syed R, Waqar S, et al. Self-medication amongst university students of Karachi: prevalence, knowledge and attitudes. J Pak Med Assoc. 2008;58(4):214-217.
19. Anjum Q, Siddiqui H, Ahmed Y, et al. Knowledge of students regarding hepatitis and HIV/AIDS of a private medical university in Karachi. J Pak Med Assoc. 2005;55(7):285-288.

20. Ismail L. Gender gap in higher education: Perspective on factors influencing enrolment in Malaysian universities: A University of Malaya sample. The Online Journal of Quality in Higher Education. 2015;2(4):35-45

21. Ming OK. Why the lower intake of males in public universities Malaysiakini; 2016.

22. Tan YM, Goh KL, Muhidayah R, et al. Prevalence of irritable bowel syndrome in young adult Malaysians: a survey among medical students. $J$ Gastroenterol Hepatol. 2003;18(12):1412-1416.

23. Yusoff MS, Rahim AF, Yaacob MJ. Prevalence and sources of stress among Universiti Sains Malaysia medical students. The Malaysian journal of medical sciences. 2010;17(1):30.

24. Al Hussaini R, Al-Kandari M, Hamadi T, et al. Dental health knowledge, attitudes and behaviour among students at the Kuwait University Health Sciences Centre. Med Princ Pract. 2003;12(4):260-265.

25. Hebert PC, Meslin EM, Dunn EV. Measuring the ethical sensitivity of medical students: a study at the University of Toronto. $J$ Med Ethics. 1992;18(3):142-147.

26. Ahmad A, Sann LM, Rahman HA. Factors associated with knowledge, attitude and practice related to hepatitis $\mathrm{B}$ and $\mathrm{C}$ among international students of Universiti Putra Malaysia. BMC public health. 2016;16(1):611.

27. Ilesanmi O, Alele FO. Knowledge, attitude and perception of Ebola virus disease among secondary school students in Ondo State, Nigeria, October, 2014. PLoS Curr. 2016;8.

28. Khan MU, Ahmad A, Ejaz A, et al. Comparison of the knowledge, attitudes, and perception of barriers regarding adverse drug reaction reporting between pharmacy and medical students in Pakistan. $J$ Educ Eval Health Prof. 2015;12:28

29. Nakhaee A, Ghassemi AR, Torshizi Z, et al. Knowledge of Dentistry, Medicine, and Pharmacy Students about Psychedelic Drugs in Kerman University of Medical Sciences. Addict Health. 2009;1(2):92-7.

30. Chua KB. Epidemiology of chikungunya in Malaysia: 2006-2009. Med J Malaysia. 2010;65(4):277-282.

31. Travelers' Health. Centers for Disease Control and Prevention. 2015.

32. Bedoya-Arias JE, Murillo-García DR, Bolaños-Muñoz E, et al. Healthcare students and workers' knowledge about epidemiology and symptoms of chikungunya fever in two cities of Colombia. J Infect Dev Ctries. 2015;9(3):330-332.

33. Gul S, Aziz S, Tariq S. Chikungunya-The Need for Instigating Awareness in Pakistan. Int J Pharm Res Scholars. 2014;3(2):520-523.

34. Hoarau JJ, Bandjee MC, Trotot PK, et al. Persistent chronic inflammation and infection by Chikungunya arthritogenic alphavirus in spite of a robust host immune response. J Immunol. 2010;184(10):5914-5927.

35. Tsetsarkin KA, Vanlandingham DL, McGee CE. A single mutation in chikungunya virus affects vector specificity and epidemic potential. PLoS Pathog. 2007;3(12):e201. 